\title{
Kinship Caregivers: Communicating with Children about a Parent's Deployment ${ }^{1}$
}

\author{
Elizabeth Thomas and Larry F. Forthun ${ }^{2}$
}

\section{Introduction}

The deployment of a military parent is undoubtedly a difficult time for children. There are changes in family routines, concerns for the parent's well-being, and ultimately, changes in the child's quality of life. This is especially true if the military child is being cared for by a relative, or kinship parent such as a grandparent, aunt, uncle, or older sibling. Care by a relative may mean a change in household, a change in schools, and a change in friends. The child, in effect, may have to experience a kind of personal deployment from their own home.

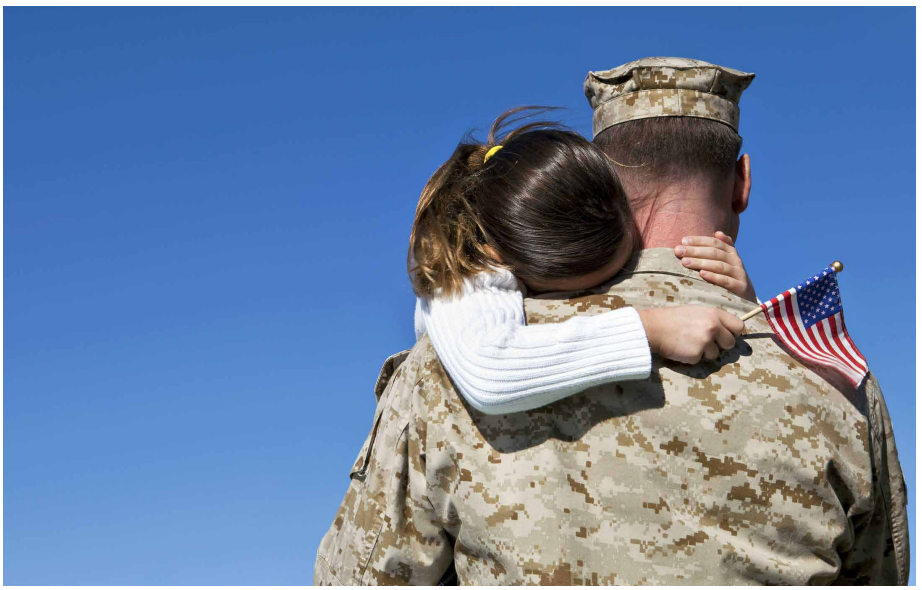

Credits: Thinkstockphotos.com

To help children cope with these changes, it is important for the kinship parent to effectively communicate with the child about the deployment and the deployed parent. Promoting and practicing effective communication skills based on the developmental stage of the child will help ensure that the child knows that there is someone available if the child needs to talk and that the child is safe and cared for Healthy communication between the kinship parent and the child is something that will safeguard against emotional and behavioral problems and can lead to improvements in the child's overall sense of well-being.

\section{Communication at Developmental Stages}

For most of us, communication is simple. It's something we do every day. We regularly communicate with our children, family members, friends, and co-workers about day-to-day things. However, when the topic of the conversation turns to more difficult issues, we are often at a loss for words. When a child is anxious about the military parent, what do we say?

There are two things you can do to be an effective communicator. First, be a good listener. Most people believe that good communicators are good because they know the right words to say. In fact, good communicators are good because they know how to listen effectively through maintaining appropriate eye contact, showing empathy, and listening nonjudgmentally. Second, know who you are talking to. Good communicators know that how you

1. This document is FCS2329, one of a series of the Family Youth and Community Sciences Department, Florida Cooperative Extension Service, Institute of Food and Agricultural Sciences, University of Florida. Original publication date March 2013. Visit the EDIS website at http://edis.ifas.ufl.edu.

2. Elizabeth Thomas, Kids Central, Inc., Ocala FL; and Larry F. Forthun, assistant professor, Department of Family Youth and Community Sciences, Institute of Food and Agricultural Sciences, University of Florida, Gainesville, FL 32611. 
communicate with people will depend on the age and abilities of the person. Younger children have different needs than older children and this will require a slightly different approach to communication.

\section{Zero to 3}

From birth to three, children are beginning to learn how to communicate. They need to be listened to, even if they are not yet old enough to form words. An infant's babbles can be mimicked back as a way of communication when changing their diapers, feeding them, and holding/playing with them (Graham 2007; Perkins and Fogarty 2005). For two and three year olds, talk often about the deployed parent and remind them that the parent loves and misses them. Explain the parent's deployment in very simple terms (e.g., "Mommy had to go do an important job") (Perkins and Fogarty 2005).

\section{Preschool}

As with toddlers, consistent care and availability will help preschoolers cope with the deployment. Be available and ready to listen (U.S. Department of Defense). Although preschoolers have stronger verbal skills than toddlers, they may still have trouble verbalizing how they feel. Listen to their ideas and pay attention to non-verbal communication such as changes in appetite, moods, or sleeping patterns. Many preschoolers show emotions through "pretend play" or artwork. Engage the preschooler with creative play to create an environment where their feelings can be discussed. Give them extra positive attention to help promote positive coping. Give preschoolers simple explanations to questions. Ask questions about how they are feeling (Graham 2007).

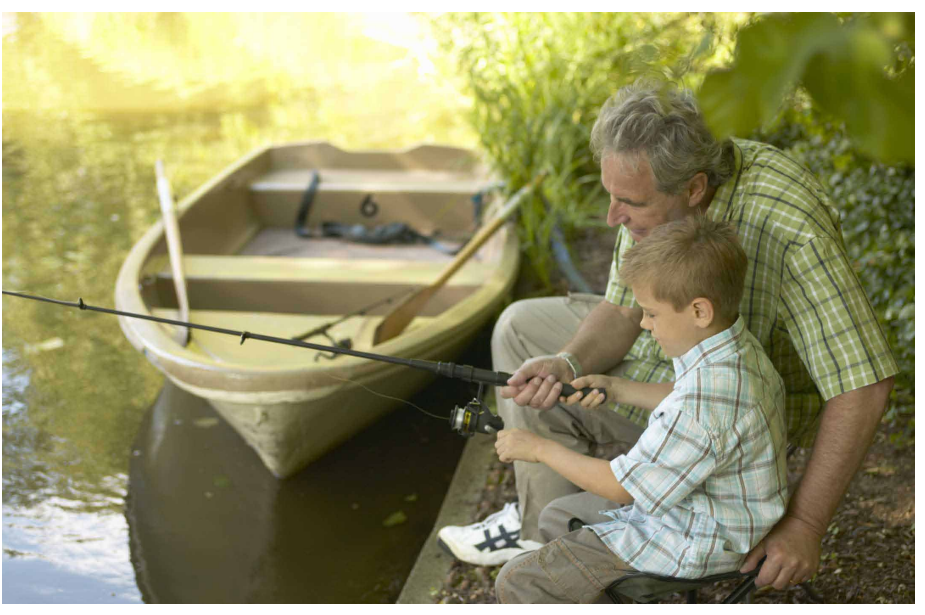

Credits: Jochen Sand, Thinkstockphotos.com

\section{School Age}

Help school-aged children express their emotions through coloring, drawing, writing, or other expressive arts (Levin, Daynard, and Dexter 2008). Reassure them that their feelings are normal, and avoid judgment or criticism (e.g., "You shouldn't be so upset") (U.S. Department of Defense). Help them learn to work through anger and frustration effectively; practice patience (Levin, Daynard, and Dexter 2008). Develop ways that the child can cope with anger or frustration, such as sports, journaling, or music. Withhold unnecessary information about the deployment that may only add to the child's anxiety. Maintain a regular routine, and involve the child if the routine has to be changed. Even if the schedule for the afternoon must change due to a conflict, alert the child as soon as possible. Ask the child questions about what they think and feel about the deployment.

\section{Pre-teen/Teenager}

Aim to develop a relationship in which the pre-teens or teens feels comfortable talking to you. Acknowledge and validate their feelings and ask questions about how they feel without being pushy (Graham 2007). Create and maintain times when the teenager knows you are available to talk, such as at mealtimes or before bed (Levin, Daynard, and Dexter 2008). Make every effort to maintain routines. Avoid taking it personally if the pre-teen/teen questions rules; teenagers often want to know the reasons for rules they feel are unreasonable.

\section{Conclusions}

Effective communication about deployment and the deployed parent is critical to helping a child learn to adjust and cope with the many changes that are occurring during deployment. It is important to remember with children of all ages, this is a tough time for them and the most important thing you can do for them is create an environment where they feel safe, secure, and know that you are someone they can talk to about their thoughts and feelings.

\section{Web Resources}

Strategic Outreach to Families of All Reservists, or SoFar, is an organization dedicated to providing online resources to military families related to deployment, preventing crises, and managing acute problems. http://www.sofarusa.org

The National Military Family Association is an organization aimed at supporting military families that is made up of military families; the staff consists if spouses, parents, and family members of military. http://militaryfamily.org 
Military Youth on the Move is a website for military children from elementary to high school. This website addresses issues with youth related to deployment, moving, and making new friends. http://apps.mhf.dod.mil/pls/ psgprod/f?p=MYOM:HOME:0

The Military Families Learning Network serves military family service professionals through engaged online communities in the areas of families, parents, and children. http://www.extension.org/militaryfamilies

\section{References}

Graham, B. 2007. U.S. Army deployment support handbook: Children and youth. Ithaca, NY: Wells Communication. Retrieved June 1, 2012 from: http://www.myarmyonesource.com/cmsresources/Army\%20OneSource/Media/ PDFs/Family\%20Programs\%20and\%20Services/Family\%20 Programs/Deployment\%20Readiness/Operation\%20 READY/DEPLOY_SPPT_HBOOK_CHILD_YOUTH.pdf

Levin, D.E., C. I. Daynard, and B. A. Dexter. 2008. The "SOFAR" guide for helping children and youth cope with the deployment and return of a parent in the national guard and other reserve components. Retrieved June 1, 2012 from: http://www.sofarusa.org/downloads/sofar_children_pamphlet.pdf

Perkins, D.F., and K. Fogarty. 2005. Active listening: A communication tool. Gainesville, FL: Cooperative Extension Service, Institute of Food and Agricultural Sciences, University of Florida. Publication number: FCS2151.

http://edis.ifas.ufl.edu/he361

U.S. Department of Defense. (n.d.). Parent's guide to the military child during deployment and reunion. Retrieved June 1, 2012 from: http://www.aap.org/sections/ uniformedservices/deployment/pdfs/parent_guide_deployment.pdf 